\title{
Experimental estimation of the mechanical and fracture properties of a new epoxy adhesive
}

\author{
J. P. R. Monteiro ${ }^{1}$, R. D. S. G. Campilho ${ }^{1 *}$, E. A. S. Marques ${ }^{2}$ and L. F. M. da Silva ${ }^{3}$
}

*Correspondence: raulcampilho@gmail.com

${ }^{1}$ Departamento de Engenharia Mecânica, Instituto Superior de Engenharia do Porto, Instituto Politécnico do Porto, Rua Dr. António Bernardino de Almeida, 431, 4200-072 Porto, Portugal Full list of author information is available at the end of the article

\begin{abstract}
The automotive industry is currently increasing its use of high performance structural adhesives in order to reduce vehicle weight and increase the crash resistance of automotive structures. To achieve these goals, the high performance adhesives employed in the automotive industry must not only have high mechanical strength but also large ductility, enabling them to sustain severe dynamic loads. Due to this complex behaviour, the design process necessary to engineering structures with these materials requires a complete knowledge of their mechanical properties. In this work, the mechanical properties of a structural epoxy, Sikapower ${ }^{\circledR} 4720$, were determined. Tensile tests were performed to determine the Young's modulus $(E)$ and tensile strength $\left(\sigma_{f}\right)$. Shear tests were performed to determine the shear modulus $(G)$ and the shear strength $\left(\tau_{f}\right)$. Tests were also performed to assess the toughness of the adhesive. For mode I toughness determination $\left(G_{\mid c}\right)$, the double-cantilever beam (DCB) test was employed. For determination of toughness under mode $\|\left(G_{\| c}\right)$, the end-notched flexure (ENF) test was performed. The data obtained from the DCB and ENF tests was analysed with the compliance calibration method (CCM), corrected beam theory (CBT) and compliance-based beam method (CBBM) techniques. The test results were able to fully mechanically characterize the adhesive and demonstrate that the adhesive has not only high mechanical strength but combines this with a high degree of ductility, which makes it adequate for use in the automotive industry.
\end{abstract}

Keywords: Structural adhesive, Bulk specimens, Thick adherend shear test, Fracture toughness

\section{Background}

The reduction of structural weight and the enhancement of vehicle safety are currently two of the most important research subjects for the automotive industry. The demand for lighter and safer structures has led the designers to increasingly employ alternative joining methods, replacing the more commonly used spot welding. Adhesive bonding is one of these methods and its use has expanded significantly, driven by the development of improved high performance adhesives and bonding techniques. While previous adhesives were relatively strong but brittle, the adhesives currently used for structural bonding by the automotive industry are designed with the aim of providing the joint with high ductility and high mechanical strength [1]. These materials are commonly referred

(c) 2015 Monteiro et al. This article is distributed under the terms of the Creative Commons Attribution 4.0 International License (http://creativecommons.org/licenses/by/4.0/), which permits unrestricted use, distribution, and reproduction in any medium, provided you give appropriate credit to the original author(s) and the source, provide a link to the Creative Commons license, and indicate if changes were made. 
as crash resistant adhesives due to their ability to plastically deform but still maintain the structure firmly bonded under significantly large loads, therefore ensuring that the structure has a large degree of energy absorption. Modern automotive structures combine multiple bonded materials and use adhesive layers with complex geometry. To efficiently design such structures, the use of finite element method (FEM) techniques is fundamental. One of the most accurate methods to model adhesive layers are cohesive zone models (CZM) to simulate adhesive failure and associated debonding. CZM are a very powerful tool for studying the behavior of adhesive joints. Cohesive elements can be easily added to FEM models. Needleman [2], Tvergaard et al. [3] and Camacho et al. [4] were among the first to adapt this technique for use in adhesive joints. A CZM improves on classical continuum mechanics modelling and can describe the fracture process and location. By using both strength and energy parameters to simulate the nucleation and advance of a fracture crack [5], these elements can fully simulate the crack progression in adhesive layers. The relationship between the stresses and displacements is governed by a traction separation law.

The experimental campaign described in this work enabled the estimation of $E, G, \sigma_{\mathrm{f}}$, $\tau_{\mathrm{f}}, G_{\mathrm{Ic}}$ and $G_{\mathrm{IIc}}$. The tensile properties of the specimen $\left(E\right.$ and $\left.\sigma_{\mathrm{f}}\right)$ were determined using the bulk tensile testing of "dog bone" specimens. This almost universal test is standardized under ISO 527:1997 [6] and its ASTM equivalent D638-03 [7]. To measure the shear properties of the adhesive ( $G$ and $\tau_{\mathrm{f}}$ ), the thick adherend shear test (TAST) was employed. This test follows the standard ISO 11003-2:1993 [8]. Another method commonly employed to assess $\tau_{\mathrm{f}}$ of adhesives is the torsion test, standardized under ASTM E143-02 [9]. The determination of $G_{\text {Ic }}$ is usually performed with the DCB specimen [10], although other common specimen geometries exist such as the tapered double-cantilever beam (TDCB) or the single edge notch bend (SENB) specimens. The DCB test is widely used because it requires relatively simple specimens and it has well defined testing procedures. Several methodologies exist that allow the derivation of $G_{\text {IC }}$ from this testing data, resulting from a linear elastic fracture mechanics analysis. During a DCB test it is assumed that a crack will stably propagate when the tensile strain energy release rate $\left(G_{\mathrm{I}}\right)$ equals $G_{\mathrm{Ic}}$. The CCM is based on the Irwin-Kies [11] equation and requires the calculation of the compliance $(C)$ relatively to the crack length $(a)$. The compliance is given by $C=\delta / P$, where $\delta$ is the displacement and $P$ is the applied load. As an alternative, the DBT uses the classical beam theory equations to assess the compliance [12] and the CBT improves on it by taking account the effects of crack tip rotation and deflection [13]. All these methods require the constant measurement of the crack location, which might be difficult or yield imprecise results. As an alternative, the CBBM uses the concept of the crack equivalent [14]. This means that it derives the crack location solely from $C$ at any given moment, negating the need to visually monitor the crack progression as required by other methods [15]. The determination of $G_{\text {IIc }}$ can be performed using three different tests by the theoretically steady-state value of shear strain energy release rate $\left(G_{\mathrm{II}}\right)$ that is attained during crack propagation. The ENF test, the end-loaded split (ELS) and the four point end-notched flexure (4ENF) test. Among these alternatives, the ENF is the most commonly used, as it does not exhibit the friction problems found in the 4ENF test and avoids the excessively large displacements found in the ELS test. The ENF has also the advantage of using a specimen mostly similar to the one used in the DCB 
tests, differing only in the loading direction. The ENF test is simply a three-point flexure test on a pre-cracked specimen. During the ENF test the relative displacement of the upper and lower specimens introduces a shearing load in a pre-cracked adhesive layer. The data from these tests can be analyzed using the same methods used for the analysis of the DCB test results.

Saldanha et al. [16] have used similar methods to perform a characterization procedure on a high elongation, high toughness epoxy adhesive. They found that such adhesive combined the high tensile strength and shear strength typical of epoxy adhesives with the high toughness of polyurethane adhesives. Similarly, García et al. [17] characterized a toughened epoxy adhesive to use in the FEM. Their experimental procedure used only tensile and shear tests to build a continuum damage model that was able to accurately simulate the mechanical behavior of complete joints. Much of the work on characterizing toughened, high elongation epoxy adhesives focuses on the study of the fracture properties, where there are significant improvements to be found. A variety of specimen types are used in these tests. Jin et al. [18] studied the mode I fracture behavior of a self-healing toughened adhesive by the TDCB test. Kim et al. [19] performed a similar characterization for a nanoparticle reinforced epoxy but used the simpler single SENB specimens for this purpose. All these tests found improvements in toughness over standard epoxy formulations.

In this work, the mechanical properties of a structural epoxy, Sikapower ${ }^{\circledR} 4720$, were determined. Tensile tests were performed to determine $E$ and $\sigma_{\mathrm{f}}$. Shear tests were performed to determine $G$ and $\tau_{\mathrm{f}}$. Tests were also performed to assess the toughness of the adhesive. For $G_{\text {Ic }}$ characterization, the DCB test was employed. For determination of $G_{\text {IIC }}$, the ENF test was performed. The data obtained from the DCB and ENF tests was analysed with the CCM, CBT and CBBM techniques. Comparison of the Sikapower ${ }^{\circledR}$ 4720 with another epoxy adhesive was also undertaken. The Araldite ${ }^{\circledR} 2015$ was chosen for this purpose because of being a direct competitor in terms of applications and being established in the market. With this work, complete data for the numerical design of bonded structures with this novel adhesive is provided, enabling the optimization of the joints and the subsequent cost and weight reduction of the structures.

\section{Methods}

Tensile tests

Figure 1 shows the specimen dimensions for the bulk specimens with dogbone shape for tensile testing, which were fabricated according to the French Standard NF T 76-142 [20]. Curing of the specimens was carried out in a steel mold [21] that permits the simultaneous production of 6 specimens (Fig. 2). The top and bottom plates of the mold were machined by computer numerical control $(\mathrm{CNC})$, and then grinded (to improve the surface finish) and hard chrome plated (to increase the abrasion resistance and facilitate demolding). The mold plate, to be placed between the top and bottom plates to produce the adhesive cavities, was laser cut. Before application of the adhesive, the mold was cleaned with acetone and demolding agent was applied. The adhesive was applied in the mold cavities by the application gun and manually spread, before being left for cure during 1 week. The tensile tests were performed in an Instron ${ }^{\circledR} 3367$ testing machine with a $30 \mathrm{kN}$ load cell, at room temperature and under displacement control $(2 \mathrm{~mm} / \mathrm{min})$. 

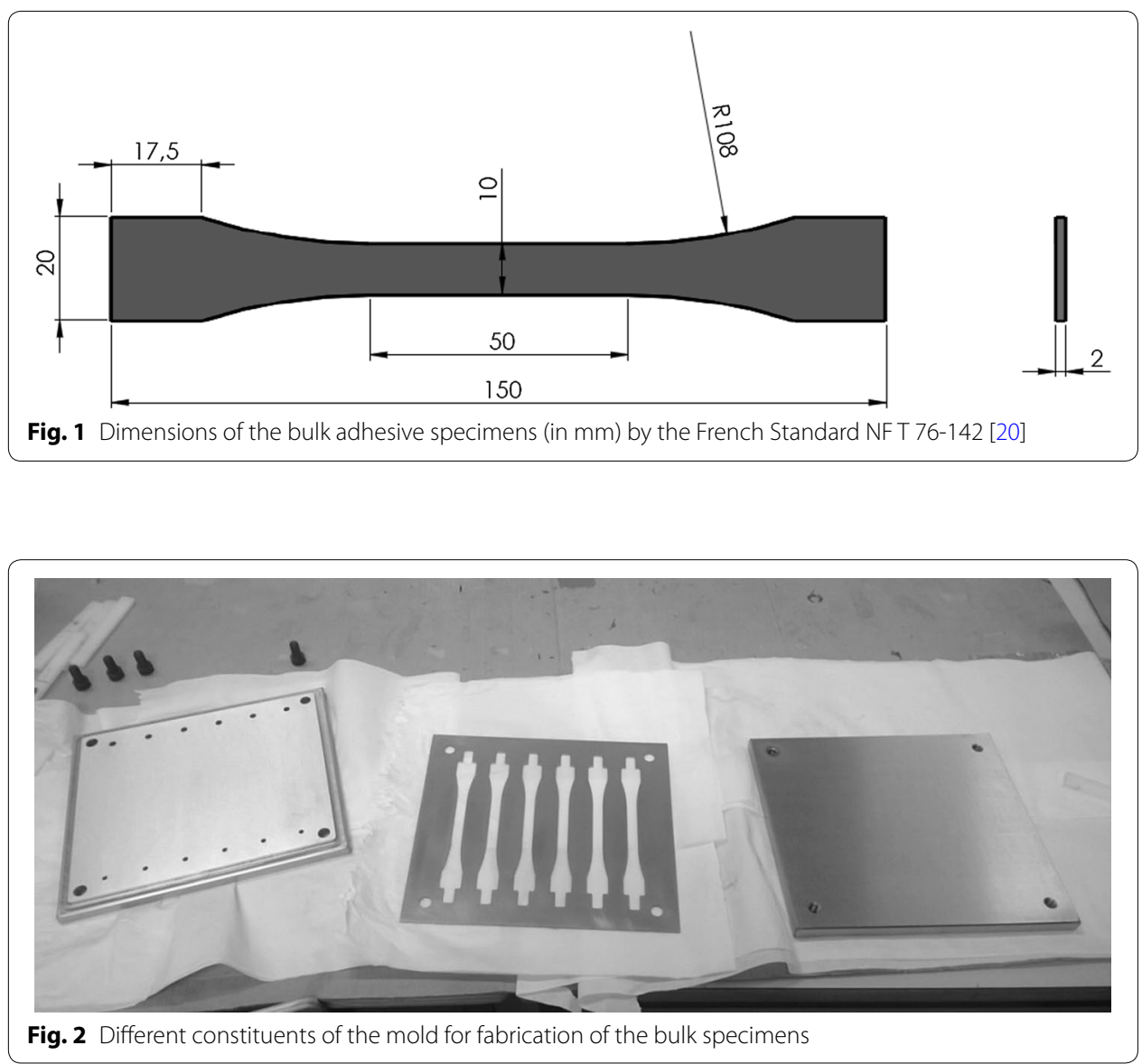

During the tests, the longitudinal strains $(\varepsilon)$ were measured with a mechanical extensometer with a base length of $25 \mathrm{~mm}$.

For the determination of the bulk tensile mechanical properties of the adhesive, the standard EN ISO 527-2 [6] was considered. $E$ was measured between values of $\varepsilon$ of 0.05 and $0.25 \%$ as

$$
E=\frac{\Delta \sigma}{\Delta \varepsilon}
$$

where $\Delta \sigma$ and $\Delta \varepsilon$ are the variations of tensile stress and strain, respectively. The yield stress $\left(\sigma_{\mathrm{y}}\right)$ was obtained for $\varepsilon=0.2 \%$, by the intercept between the tensile stress $(\sigma)$ $\varepsilon$ curve and a parallel line to the initial part of this curve. $\sigma_{\mathrm{f}}$ is calculated by the ratio between the maximum load and the initial cross section of the sample. During the test, the tensile failure strain $\left(\varepsilon_{f}\right)$ was also registered, corresponding to the maximum displacement sustained by the specimen.

\section{Shear tests}

The TAST was selected to perform the shear tests, using the adherends and machine gripping tools developed by Morais [22] in DIN C45E steel. All aspects related to the tests (e.g. geometry and dimensions) followed the ISO 11003-2 standard [8]. Surface preparation of 
the steel adherends consisted of grit blasting and cleaning with acetone. The adherends were cured in a jig (Fig. 3) that ensures the precise alignment of the adherends and correct overlap length. The specimens were assembled using $1 \mathrm{~mm}$ spacers between adherends to attain the correct value of overlap length. These spacers and all the mounting jig surfaces potentially in contact with the adhesive were coated with demolding agent to facilitate extraction of the specimens after curing. Application of the adhesive was done manually (Fig. 4a), followed by manual positioning of the adherends with application of pressure on the joints (Fig. 4b). The limiting bars were then fastened to the jig to assure the correct overlap length and the specimens left to cure for 1 week at room temperature. The longitudinal strains during the test were measured with a mechanical extensometer. Figure 5 represents the test setup. The considered test speed was $0.5 \mathrm{~mm} / \mathrm{min}$ (ISO 11003-2 standard [8]).

The ISO 11003-2 standard [8] was considered to determine the shear mechanical properties of the adhesive by TAST tests. The shear stress $(\tau)$ was calculated using the following equation

$$
\tau=\frac{P}{l \times B},
$$

where $l$ is the bond length and $B$ is the specimens' width. The expression used to calculate the shear strain $(\gamma)$ is given by

$$
\gamma=\frac{\delta}{t_{\mathrm{A}}}
$$

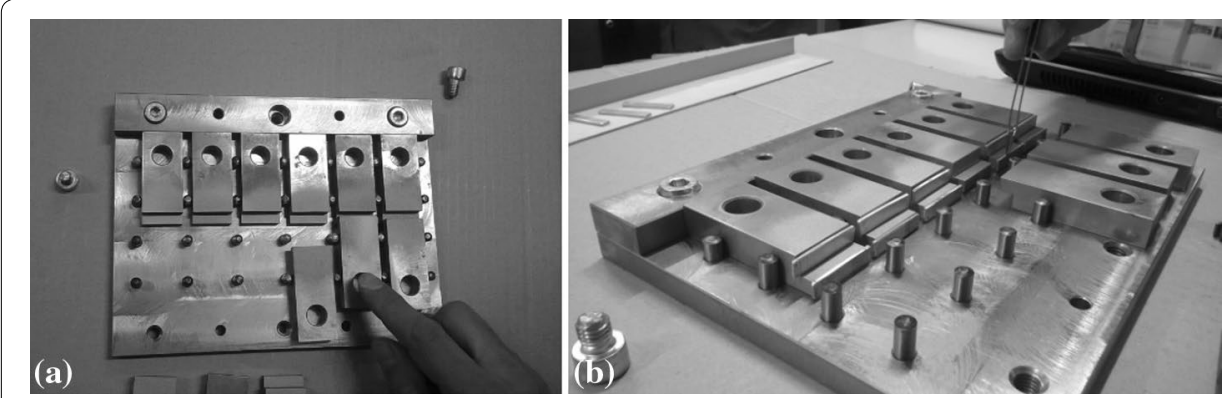

Fig. 3 Adherents placing in the jig: alignment of the adherends (a) and placement of the spacers (b)

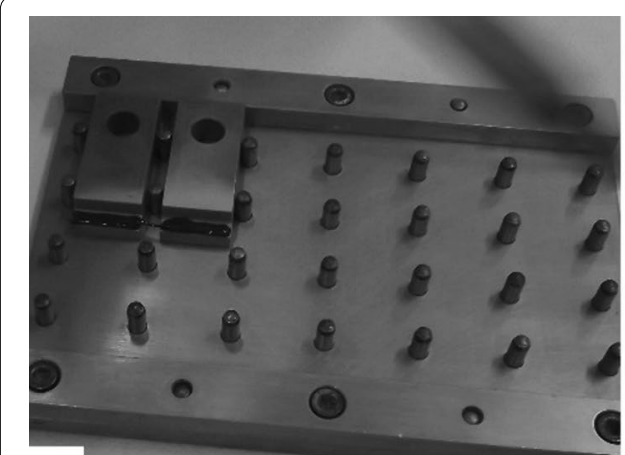

(a)

Fig. 4 Manufacturing of the TAST specimens: applying the adhesive (a) and adherends' positioning in the jig (b)

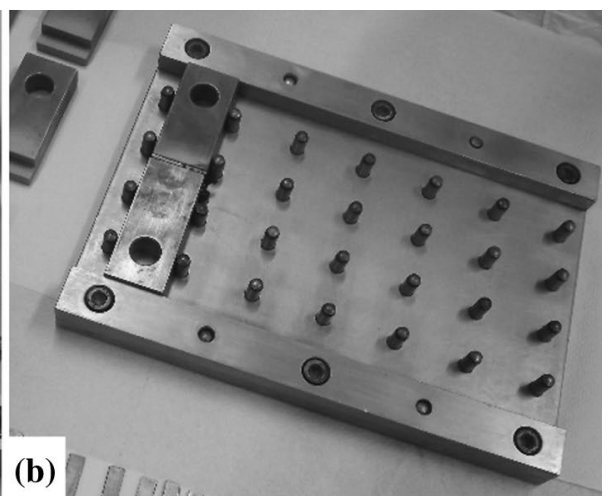

(b)

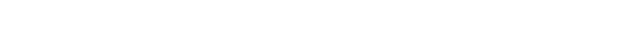




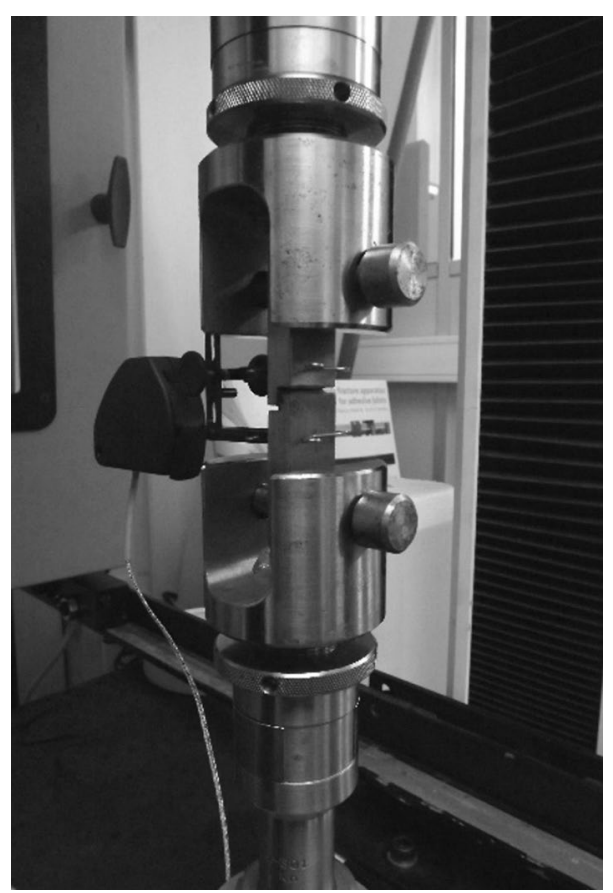

Fig. 5 TAST specimen attached to the testing machine with the mechanical extensometer

where $t_{\mathrm{A}}$ is the adhesive thickness. Subsequently, the value of $G$ was determined in the elastic portion of the $\tau-\gamma$ curve as

$$
G=\frac{\tau}{\gamma}
$$

\section{Fracture tests}

DCB tests were considered to calculate $G_{\text {Ic }}$, and ENF tests to obtain $G_{\text {IIc }}$. Both test methods used AA6082 T651 aluminum alloy adherends with the dimensions of $140 \times 25 \times 3 \mathrm{~mm}^{3}$ (DCB tests) and $230 \times 25 \times 3 \mathrm{~mm}^{3}$ (ENF tests). Previous characterization of this material in bulk tension [23] resulted in the following mechanical properties: $E=70.07 \pm 0.83 \mathrm{GPa}, \sigma_{\mathrm{y}}=261.67 \pm 7.65 \mathrm{MPa}, \sigma_{\mathrm{f}}=324 \pm 0.16 \mathrm{MPa}$ and $\varepsilon_{\mathrm{f}}=21.70 \pm 4.24 \%$. Figure 6 depicts the geometry and relevant dimensions of the DCB (a) and ENF specimens (b). The dimensions for the DCB joint are: total length $L=140 \mathrm{~mm}$, initial crack length $a_{0} \approx 55 \mathrm{~mm}$, adherend thickness $t_{\mathrm{P}}=3 \mathrm{~mm}, B=25 \mathrm{~mm}$ and $t_{\mathrm{A}}=0.2 \mathrm{~mm}$. The dimensions of the ENF specimens are: mid-span $L=100 \mathrm{~mm}$, $a_{0} \approx 60 \mathrm{~mm}, t_{\mathrm{P}}=3 \mathrm{~mm}, B=25 \mathrm{~mm}$ and $t_{\mathrm{A}}=0.2 \mathrm{~mm}$. The specimens were fabricated in a laboratory with controlled temperature and humidity. The bonding faces were prepared by grit blasting with corundum sand, cleaned with acetone and assembled in a steel mould for bonding. To obtain a constant value of $t_{\mathrm{A}}$ throughout the bonded portion of the specimens, calibrated steel spacers were inserted between the adherends, after proper preparation with demoulding agent. Moreover, at the crack tip, a sharp pre-crack was induced by a $0.1 \mathrm{~mm}$ thick razor blade between the calibrated steel spacers. After applying the adhesive, the specimens were closed following the best practices to avoid air entrapment and appearance of air bubbles within the adhesive layer. Curing was 


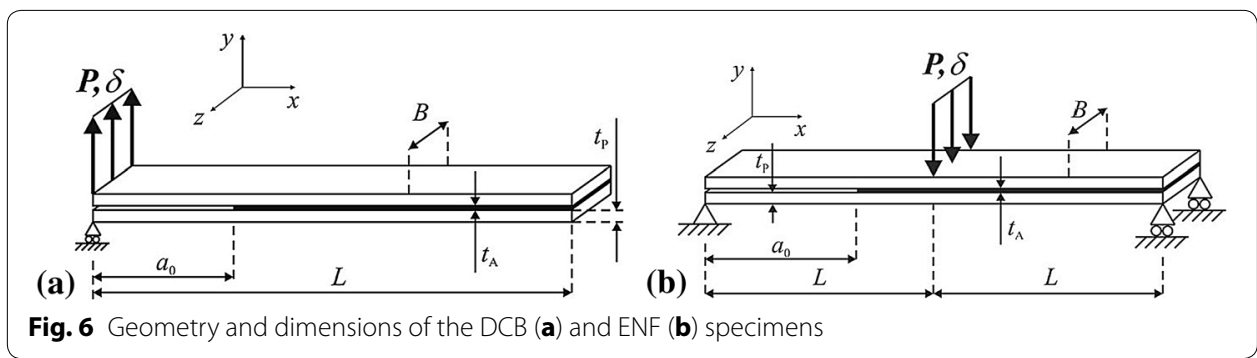

performed at room temperature. Preparation for testing consisted of removing the steel spacers, spraying the adherends' sides with brittle white paint to enable a clear identification of $a$, and gluing a black numbered scale in both adherends to aid the $a$ measurement. The testing programme involved testing six DCB and eight ENF specimens at room temperature using an Instron ${ }^{\circledR} 3367$ electro-mechanical testing machine equipped with a $30 \mathrm{kN}$ load cell. Images were captured during the tests using an 18 MPixel digital camera with no zoom and fixed focal distance to approximately $100 \mathrm{~mm}$, which enabled obtaining the values of $a$ with accuracy. The values of $a$ were then correlated with the $P$ $\delta$ data by the time elapsed since the beginning of each test.

The value of $G_{\text {Ic }}$ was evaluated by three data reduction schemes: the CCM, the CBT and the CBBM. The classical reduction schemes to estimate $G_{\text {Ic }}$ are usually based on compliance calibration or the beam theory. The CCM is based on the Irwin-Kies equation [11]

$$
G_{\mathrm{Ic}}=\frac{P^{2}}{2 B} \frac{\mathrm{d} C}{\mathrm{~d} a},
$$

where $C=\delta / P$. Cubic polynomials $\left(C=C_{3} a^{3}+C_{2} a^{2}+C_{1} a+C_{0}\right)$ were used to fit the $C=f(a)$ curves, leading to

$$
G_{\mathrm{Ic}}=\frac{P^{2}}{2 B}\left(3 C_{3} a^{2}+2 C_{2} a+C_{1}\right) .
$$

Beam theories were also used to measure $G_{\mathrm{Ic}}$. Using the CBT, $G_{\mathrm{Ic}}$ is obtained using [24]

$$
G_{\mathrm{Ic}}=\frac{3 P \delta}{2 B(a+|\Delta|)},
$$

where $\Delta$ is a crack length correction for crack tip rotation and deflection, obtained as specified in the standard ISO 15024 [25]. The CBBM is a relatively straightforward but robust method, based on an equivalent crack length $\left(a_{\mathrm{eq}}\right)$, and it only depends on the specimen's compliance during the test. Applied to the DCB test specimen, it gives

$$
G_{\mathrm{Ic}}=\frac{6 P^{2}}{B^{2} t_{\mathrm{P}}}\left(\frac{2 a_{\mathrm{eq}}^{2}}{t_{\mathrm{P}}^{2} E_{\mathrm{f}}}+\frac{1}{5 G_{\mathrm{AD}}}\right) .
$$

Detailed explanations of the method can be found in the work of Campilho et al. [26]. The value of $a_{\text {eq }}$ is estimated from the current specimen compliance and taking into 
consideration the damage zone, $E_{\mathrm{f}}$ is a corrected flexural modulus to account for stress concentrations at the crack tip and stiffness variability between specimens, and $G_{\mathrm{AD}}$ is the shear modulus of the adherends.

The following techniques were tested for the ENF specimen: CCM, CBT and CBBM [27]. The classical data reduction schemes to obtain $G_{\text {IIc }}$ are usually based on compliance calibration or beam theories. The CCM is based on the Irwin-Kies equation [28]

$$
G_{\text {IIc }}=\frac{P^{2}}{2 B} \frac{\mathrm{d} C}{\mathrm{~d} a} \text {. }
$$

Cubic polynomials $\left(C=C_{1} a^{3}+C_{0}\right)$ were used to fit the $C=\mathrm{f}(a)$ curves, resulting into

$$
G_{\text {IIc }}=\frac{3 P^{2} C_{1} a^{2}}{2 B} \text {. }
$$

Beam theories were also used to measure $G_{\text {IIc }}$. The CBT, which accounts for crack length corrections to consider the effects of shear deformation, was proposed by Wang and Williams [29] and is written as

$$
G_{\text {IIc }}=\frac{9\left(a+0.42 \Delta_{\mathrm{I}}\right)^{2} P^{2}}{16 B^{2} E_{\mathrm{x}} t_{\mathrm{P}}^{3}}
$$

where $E_{\mathrm{x}}$ is the adherends $E$ value in the length direction and $\Delta_{1}$ is a crack length correction to account for shear deformation [27]

$$
\Delta_{\mathrm{I}}=t_{\mathrm{P}} \sqrt{\frac{E_{\mathrm{x}}}{11 G_{\mathrm{xy}}}\left[3-2\left(\frac{\Gamma}{1+\Gamma}\right)^{2}\right]},
$$

in which $G_{\mathrm{xy}}$ is the in-plane shear modulus of the adherends and $\Gamma$ is given by

$$
\Gamma=1.18 \sqrt{\frac{E_{\mathrm{x}} E_{\mathrm{y}}}{G_{\mathrm{xy}}}},
$$

where $E_{\mathrm{y}}$ is the value of $E$ of the adherends in the thickness direction. The CBBM was also developed for the ENF specimen [27], enabling the estimation of $G_{\text {IIc }}$ only using the experimental compliance. This technique relies on $a_{\mathrm{eq}}$, which is computed based on the current specimen's compliance and accounts for the fracture process zone (FPZ) effects at the crack tip (not taken into account when the real value of $a$ is considered). $G_{\text {IIc }}$ can be obtained by the following expression

$$
G_{\mathrm{IIc}}=\frac{9 P^{2} a_{\mathrm{eq}}^{2}}{16 B^{2} E_{\mathrm{f}} t_{\mathrm{P}}^{3}}
$$

Detailed explanations of the method can be found in Ref. [27]. Equally to the DCB tests, $E_{\mathrm{f}}$ is an equivalent flexural modulus obtained from the specimen's initial compliance and value of $a_{0}$. 


\section{Results and discussion}

\section{Tensile tests}

Figure 7 shows the $\sigma-\varepsilon$ curves of the six bulk tensile tests, revealing the high repeatability of the results, apart from some deviations in the value of $\varepsilon_{\mathrm{f}}$. All failures were smooth without voids or porosities. Table 1 summarizes the tensile mechanical properties of the bulk tests to the adhesive Sikapower ${ }^{\circledR} 4720\left(P_{\max }\right.$ and $\delta_{\max }$ are the maximum load and the maximum displacement, respectively).

In the present work, $\sigma_{\mathrm{f}}=27.519 \pm 0.845 \mathrm{MPa}$ was found for the Sikapower ${ }^{\circledR} 4720$, slightly higher than the manufacturer's value of $24 \mathrm{MPa}$. However, the percentile standard deviation of only $3.1 \%$ clearly shows the repeatability of the results obtained. Possible causes for this discrepancy are different curing parameters (time and/or temperature) or test protocol. The value of $\varepsilon_{\mathrm{f}}(1.973 \pm 0.343 \%)$ was smaller than that postulated by the manufacturer (3\%). This difference can be related to small fabrication defects that would prevent the full plasticity of the adhesive to develop in the bulk tests. On the other hand, $E$ was higher that the reference value $(2052.477 \pm 84.818 \mathrm{MPa}$ against $1900 \mathrm{MPa}$, respectively). The curing conditions, testing temperature and humidity, and also method used to estimate $E$ may be on the origin of this difference. $\sigma_{\mathrm{y}}$ is not available for comparison.

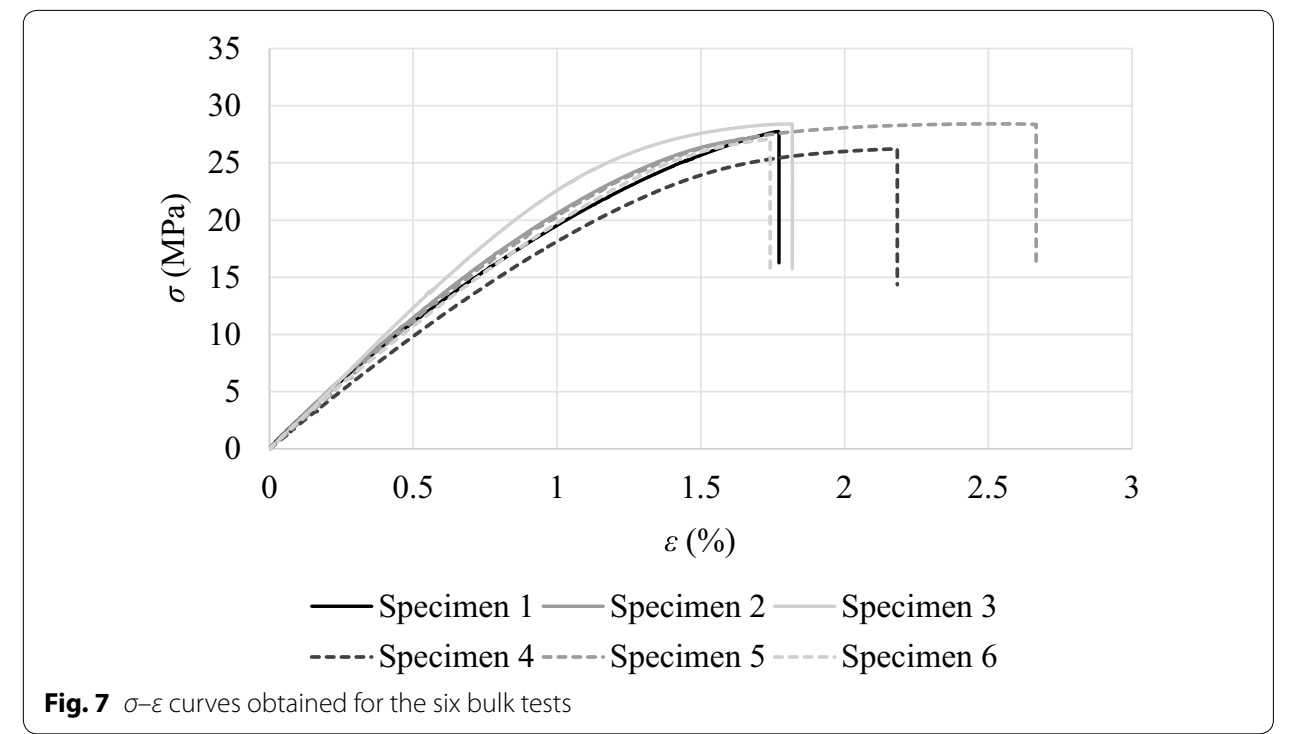

Table 1 Bulk mechanical properties in tension of the adhesive Sikapower ${ }^{\circledR} \mathbf{4 7 2 0}$

\begin{tabular}{lllllll}
\hline Specimen & $\boldsymbol{P}_{\mathbf{m a x}}(\mathbf{N})$ & $\boldsymbol{\delta}_{\mathbf{m a x}}(\mathbf{m m})$ & $\boldsymbol{\sigma}_{\mathbf{y}}(\mathbf{M P a})$ & $\boldsymbol{\sigma}_{\mathbf{f}}(\mathbf{M P a})$ & $\boldsymbol{\varepsilon}_{\mathbf{f}}(\%)$ & $\boldsymbol{E}(\mathbf{M P a})$ \\
\hline 1 & 822.512 & 1.428 & 22.600 & 27.746 & 1.762 & 2162.285 \\
2 & 886.882 & 1.861 & 20.048 & 27.212 & 1.755 & 2013.104 \\
3 & 840.769 & 1.690 & 26.366 & 28.399 & 1.815 & 1988.688 \\
4 & 822.810 & 1.943 & 21.979 & 26.228 & 2.183 & 1992.987 \\
5 & 842.490 & 2.265 & 25.030 & 28.420 & 2.584 & 2160.623 \\
6 & 803.614 & 1.755 & 23.691 & 27.109 & 1.741 & 1997.173 \\
Average & 836.513 & 1.824 & 23.286 & 27.519 & 1.973 & 2052.477 \\
Standard deviation & 28.485 & 0.279 & 2.252 & 0.845 & 0.343 & 84.818 \\
\hline
\end{tabular}


Table 2 evaluates the tensile mechanical properties of the Sikapower ${ }^{\circledR} 4720$ with another epoxy adhesive, the Araldite ${ }^{\circledR} 2015$ [30]. Comparing the two adhesives, the Sikapower ${ }^{\circledR}$ 4720 excels in $\sigma_{\mathrm{f}}, E$ and $\sigma_{\mathrm{y}}$, while the Araldite ${ }^{\circledR} 2015$ has a higher value of $\varepsilon_{\mathrm{f}}$.

\section{Shear tests}

Figure 8 presents the $\tau-\gamma$ curves of the adhesive Sikapower ${ }^{\circledR} 4720$. Identically to the previous analysis, a high repeatability between specimens is found regarding the elastic stiffness, shear strength and ductility (except for specimen 1, which showed a significantly smaller value of maximum shear strain, $\gamma_{\mathrm{f}}$, possibly due to fabrication related issues). The values of $\gamma_{\mathrm{f}}$ were calculated from the sharp drop of the load sustained by the specimens immediately before complete failure. Figure 9 represents the followed procedure to calculate the shear yield stress $\left(\tau_{\mathrm{y}}\right)$, using the intercept between the $\tau-\gamma$ curve and a line parallel with the same initial slope of the $\tau-\gamma$ curve but offset by $\gamma=0.2 \%$. All failures were cohesive in the adhesive layer. Table 3 presents the collected shear mechanical properties from the TAST tests to the adhesive Sikapower ${ }^{\circledR} 4720$. There is generally a good correspondence between specimens for each measured property, with a standard deviation below $10 \%$. Only for $\delta_{\max }(37.1 \%)$ and $\gamma_{\mathrm{f}}(34.0 \%)$ this was not observed. The deviations between specimens regarding $\delta_{\max }$ are related to premature failures, possibly induced by fabrication defects, or $t_{\mathrm{A}}$ variations to the expected design value induced during fabrication. The scatter in the values of $\gamma_{\mathrm{f}}$ is directly related to the $\delta_{\max }$ variations.

Table 2 Tensile comparative evaluation between the Sikapower ${ }^{\circledR} 4720$ and the Araldite ${ }^{\circledR}$ 2015 [30]

\begin{tabular}{lcccc}
\hline Properties & $\boldsymbol{\sigma}_{\mathbf{f}}(\mathbf{M P a})$ & $\boldsymbol{\varepsilon}_{\mathbf{f}}(\%)$ & $\boldsymbol{E}(\mathbf{M P a})$ & $\boldsymbol{\sigma}_{\mathbf{y}}(\mathbf{M P a})$ \\
\hline SikaPower $^{\circledR} 4720$ & $27.519 \pm 0.845$ & $1.973 \pm 0.343$ & $2052.477 \pm 84.818$ & $23.286 \pm 2.252$ \\
Araldite $^{\circledR} 2015$ & $21.63 \pm 1.61$ & $4.77 \pm 0.15$ & $1850 \pm 210$ & $12.63 \pm 0.61$ \\
\hline
\end{tabular}

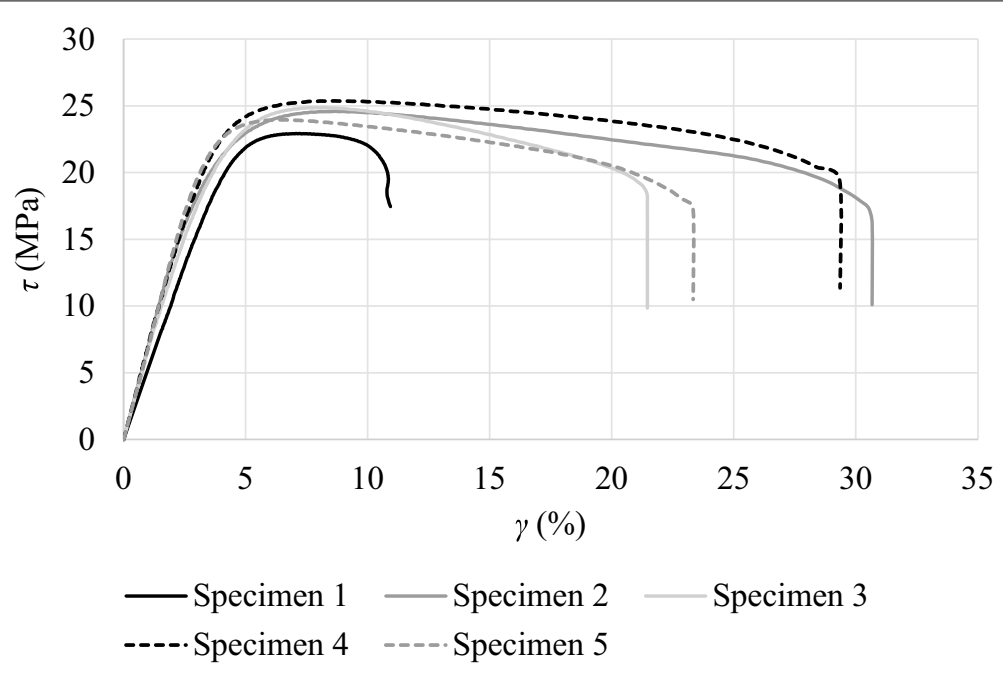

Fig. $8 T-\gamma$ curves obtained for the five TAST tests 


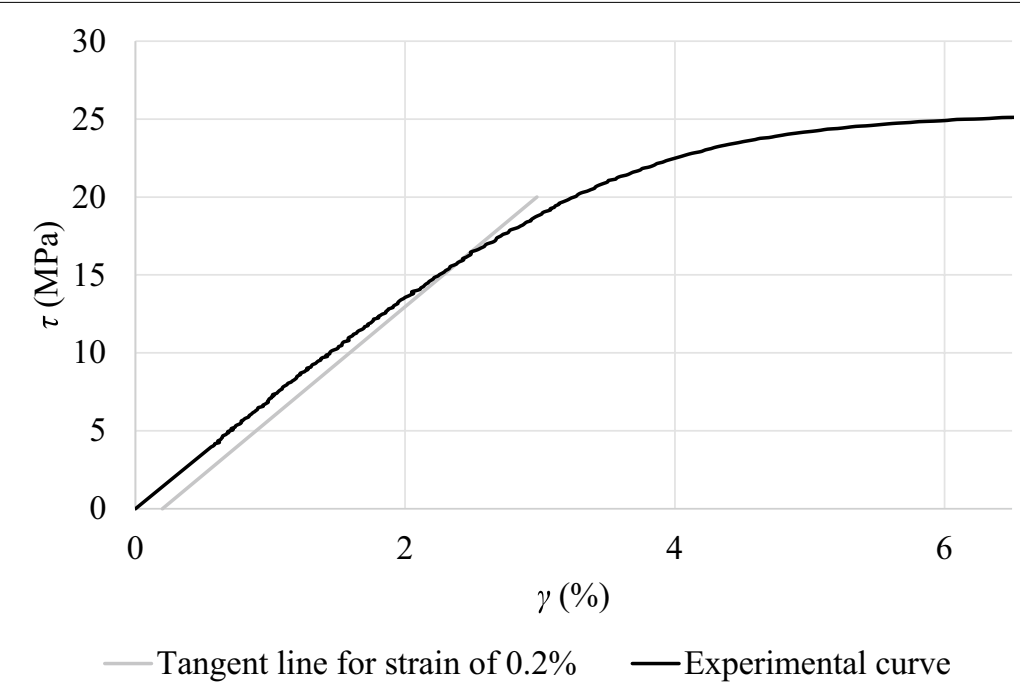

Fig. 9 Method to estimate $\tau_{y}$ for a single specimen, considering a line offset by $\gamma=0.2 \%$

Table 3 TAST mechanical properties in shear of the adhesive Sikapower ${ }^{\circledR} 4720$

\begin{tabular}{lllllll}
\hline Specimen & $\boldsymbol{P}_{\max }(\mathbf{N})$ & $\boldsymbol{\delta}_{\max }(\mathbf{m m})$ & $\boldsymbol{\tau}_{\mathbf{y}}(\mathbf{M P a})$ & $\boldsymbol{\tau}_{\mathbf{f}}(\mathbf{M P a})$ & $\boldsymbol{\gamma}_{\mathbf{f}}(\mathbf{\%})$ & $\boldsymbol{G}(\mathbf{M P a})$ \\
\hline 1 & 2865.967 & 0.071 & 15.213 & 22.928 & 10.936 & 697.567 \\
2 & 3073.479 & 0.213 & 14.817 & 24.588 & 30.669 & 727.154 \\
3 & 3108.062 & 0.142 & 13.539 & 24.864 & 21.460 & 770.566 \\
4 & 3171.353 & 0.217 & 14.502 & 25.371 & 29.351 & 819.194 \\
5 & 2994.543 & 0.149 & 16.309 & 23.956 & 23.333 & 739.212 \\
Average & 3042.681 & 0.159 & 14.876 & 24.341 & 23.150 & 750.738 \\
Standard deviation & 117.606 & 0.059 & 1.012 & 0.941 & 7.859 & 46.356 \\
\hline
\end{tabular}

The TAST tests revealed a higher average value of $\tau_{\mathrm{f}}$ than that provided by the manufacturer's sheet. Actually, the obtained value was $24.341 \pm 0.941 \mathrm{MPa}$ against an expected value of $14 \mathrm{MPa}$. However, the percentile standard deviation (3.9\%) is extremely low and all failures were cohesive, which validates the obtained results. It was not possible to compare $\gamma_{\mathrm{f}}$ because of absence of reference data. The obtained results revealed some scatter between specimens $(23.150 \pm 7.859 \%)$, which is due to the difference in specimen 1 . This value of $\gamma_{\mathrm{f}}$ clearly corresponds to a highly ductile adhesive. $G$ measurements resulted in a value of $750.738 \pm 46.356 \mathrm{MPa}$ (percentile deviation of $6.2 \%)$. Due to the isotropic nature of the adhesive, $E$ and $G$ can be used to obtain the Poisson's ratio $(v)$, which gave 0.367 and is in agreement with typical values for these adhesives. It was not possible to compare $\tau_{\mathrm{y}}$ because of the lack of information. Table 4 evaluates the shear mechanical properties of the adhesive Sikapower ${ }^{\circledR} 4720$ against the Araldite ${ }^{\circledR} 2015$ [30]. All values of the Sikapower ${ }^{\circledR} 4720$ overshoot those of the Araldite ${ }^{\circledR}$ 2015 except $\gamma_{\mathrm{f}}$. Moreover, $\tau_{\mathrm{y}}$ is much similar between both adhesives.

\section{Tensile fracture tests}

The $P-\delta$ curves of the six DCB tests are presented in Fig. 10. $P$ initially increases linearly, as the energy stored in the specimen increases. When $G_{I}$ reaches its critical value, 
Table 4 Shear comparative evaluation between the Sikapower ${ }^{\circledR} 4720$ and the Araldite ${ }^{\circledR}$ 2015 [30]

\begin{tabular}{lccccc}
\hline Properties & $\boldsymbol{\tau}_{\mathbf{f}}(\mathbf{M P a})$ & $\boldsymbol{\boldsymbol { V } _ { \mathbf { f } } ( \mathbf { \% } )}$ & $\boldsymbol{G}(\mathbf{M P a})$ & $\boldsymbol{U}$ & $\boldsymbol{\tau}_{\mathbf{y}}(\mathbf{M P a})$ \\
\hline SikaPower $^{\circledR} 4720$ & $24.341 \pm 0.941$ & $23.150 \pm 7.859$ & $750.738 \pm 46.356$ & 0.367 & $14.876 \pm 1.012$ \\
Araldite $^{\circledR}$ 2015 & $17.9 \pm 1.8$ & $43.9 \pm 3.4$ & $560 \pm 210$ & $0.33^{\mathrm{a}}$ & $14.6 \pm 1.3$ \\
\hline
\end{tabular}

a Manufacturer's value

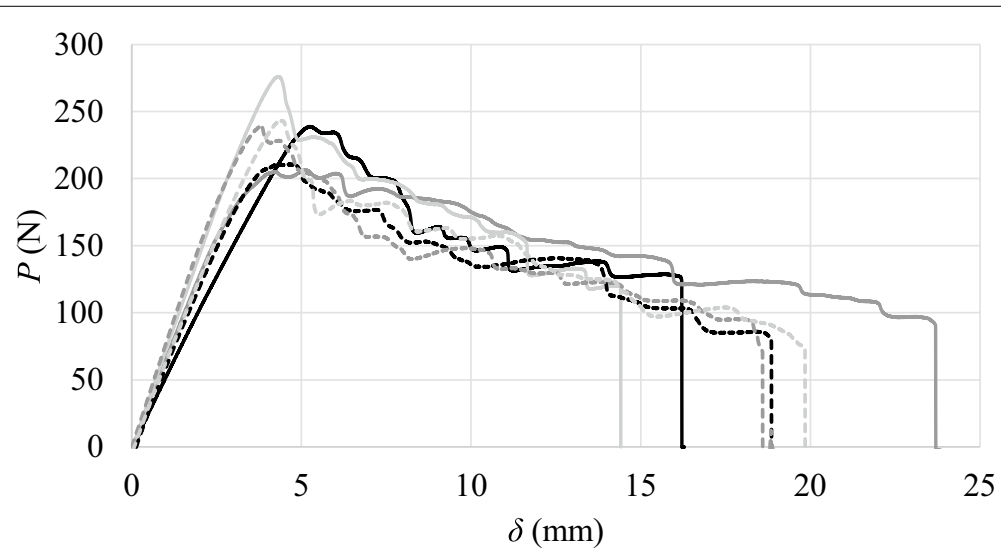

- Specimen $1 \longrightarrow$ Specimen $2-$ Specimen 3

-----Specimen 4 -----Specimen 5 ----Specimen 6

Fig. $10 P-\delta$ curves for the DCB specimens

$G_{\mathrm{Ic}}$, the crack starts to grow, and a reduction of $P$ takes place because of the increasing bending moment induced by bigger $a$ values. The curves of the several specimens showed a good correspondence, although with minor variations in the initial stiffness on account of different values of $a_{0}$. The $R$-curves were built from the $P-\delta$ curves following the previously mentioned data reduction methods, allowing to relate $G_{\mathrm{I}}$ with $a$ or $a_{e q}$ during the crack growth phase of each test [31]. Ideally, the $R$-curves are horizontal lines, although experimentally fluctuations may occur due to issues such as poor adhesive mixture, adhesion problems, defects and unstable crack growth. Figure 11 shows the $R$-curves by the different methods for a representative specimen of the DCB tests. It should be mentioned that, for the CCM, it is necessary to derive the $C=f(a)$ curve and to differentiate it. The $C=f(a)$ curve should span from the beginning of crack propagation up to the specimen's failure. For the particular specimen of Fig. 11, the $R$-curves are practically overlapped, resulting in consistent measurements of $G_{\text {Ic }}$. The CBBM has the advantage of not requiring the measurement of $a$, unlike happens with the CCM and CBT, which highly reduces the time required in the analysis and prevents errors in the measurement of $a$. The CCM still adds another source of error in the data analysis, because of the approximation taken in the calculation of $\mathrm{d} C / \mathrm{d} a$, which is performed by taking the derivative of the $C=f(a)$ curve after fitting cubic polynomials [24]. After performing all the tests, fully cohesive failures were obtained for all DCB specimens. Table 5 summarizes the values of $G_{\text {Ic }}$ by the different methods for all specimens, and also $P_{\max }$ and $\delta_{\max }$ for each specimen. The $G_{\mathrm{Ic}}$ data is highly consistent for each specimen between 


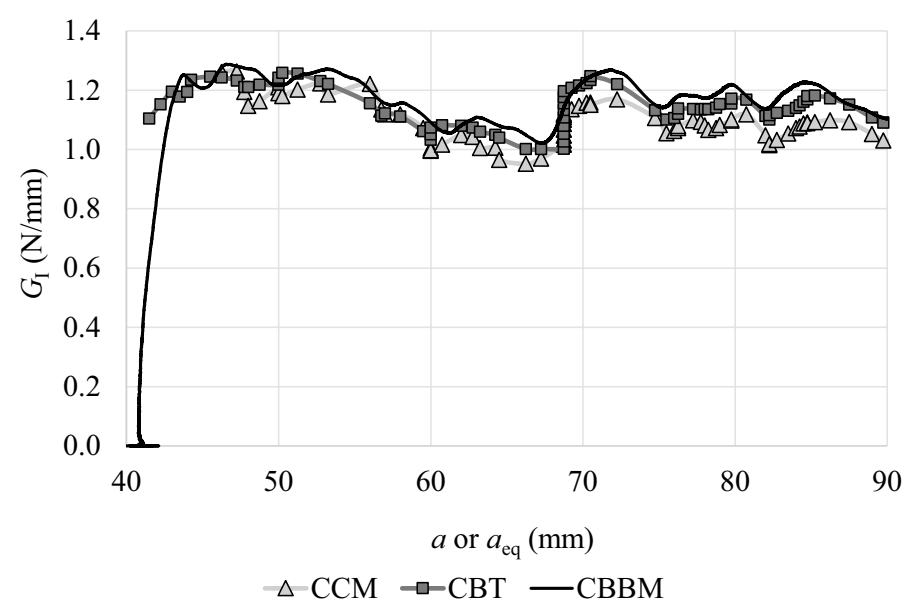

Fig. $11 C C M, C B T$ and CBBM R-curves for a DCB specimen

Table 5 Values of $G_{\mathrm{Ic}}$ obtained by the different data reduction methods from the DCB tests

\begin{tabular}{lccccr}
\hline Specimen & $\boldsymbol{P}_{\max }(\mathbf{N})$ & $\boldsymbol{\delta}_{\max }(\mathbf{m m})$ & \multicolumn{2}{l}{$\boldsymbol{G}_{\mathbf{l c}}(\mathbf{N} / \mathbf{m m})$} & \\
\cline { 5 - 6 } & & & $\mathbf{C C M}$ & $\mathbf{C B T}$ & CBBM \\
\hline 1 & 238.825 & 16.287 & 1.249 & 1.317 & 1.363 \\
2 & 206.584 & 23.846 & 1.395 & 1.443 & 1.401 \\
3 & 276.072 & 14.413 & 1.350 & 1.447 & 1.598 \\
4 & 210.687 & 19.150 & 1.059 & 1.174 & 1.186 \\
5 & 239.236 & 19.022 & 1.067 & 1.120 & 1.173 \\
6 & 243.150 & 19.948 & 1.084 & 1.168 & 1.040 \\
Average & 235.759 & 18.778 & 1.201 & 1.278 & 1.294 \\
Standard deviation & 23.025 & 2.958 & 0.138 & 0.132 & 0.182 \\
\hline
\end{tabular}

methods, and between specimens of each method (small values of standard deviation). However, the $G_{\text {Ic }}$ values of the CBBM were slightly higher than for the other methods. Nonetheless, this is regarded as the most robust method since it fully accounts for the FPZ and it is not affected by possible measurement errors of $a$.

After the analysis of all DCB specimens, no significant differences were found in the $R$-curves when comparing all considered data reduction methods. The measured values of $G_{\text {Ic }}$ for each specimen were close between data reduction methods. No data is available from the manufacturer regarding this parameter. Evaluated against the CBBM, which is regarded as the most reliable method by not requiring measurement of $a$ and including the FPZ effects in the results, the observed differences to the other methods were $7.2 \%(\mathrm{CCM})$ and $1.2 \%$ (CBT). Between specimens of the same method, the percentile deviations were $11.5 \%(\mathrm{CCM}), 10.3 \%$ (CBT) and $14.1 \%$ (CBBM). The current adhesive has $G_{\text {Ic }}=1.294 \pm 0.182 \mathrm{~N} / \mathrm{mm}$ (CBBM values) compared to $G_{\text {Ic }}=0.43 \pm 0.02 \mathrm{~N} / \mathrm{mm}$ of the Araldite ${ }^{\circledR} 2015$ [30], which corresponds to an excess of nearly three times. 


\section{Shear fracture tests}

Figure 12 compares the $P-\delta$ curves obtained in the eight ENF tests. For this particular test, eight specimens were considered to safeguard possible unstable crack propagations in some specimens, prone to occur in the ENF test. The general shape of the curves is in agreement between specimens, although one of these has a smaller elastic stiffness induced by a higher value of $a_{0}$. After $P_{\max }$ is attained, the load starts to decrease, which corresponds to the interest part of the ENF tests, in which $G_{\text {IIc }}$ is measured. Afterwards, the load increases again when the FPZ reaches the vicinity of the loading cylinder. This portion of the curves was truncated because it is no longer valid for the measurement of $G_{\text {IIc }}$. Figure 13 compares the $R$-curves of a single specimen by the CCM, CBT and CBBM. In an identical manner to the DCB specimens, these $R$-curves correlate $G_{\mathrm{II}}$ with $a$ or $a_{\text {eq }}$ and their steady-state value during the crack propagation phase provides an estimation of $G_{\text {IIc }}$. For the specimen depicted in the figure, the valid crack propagation region ranged between $84 \leq a_{\mathrm{eq}} \leq 92 \mathrm{~mm}$ (CBBM curve). After this region, a gradual increase of $G_{\mathrm{II}}$ was found related to the FPZ reaching the loading cylinder and biasing the measured value of $G_{\text {IIc }}$. The full set of $G_{\text {IIc }}$ values obtained by the three methods is shown in Table 6 , together with the $P_{\max }$ and $\delta_{\max }$ values for all specimens. The results for specimen 6 were discarded from the analysis due to a significant offset to the typical values obtained for the other specimens. Equally to the DCB results and owing to previous evidence regarding these methods [27], the CBBM is considered the most reliable.

In accordance with the previous tests, the ENF tests also revealed a high repeatability. The $G_{\text {IIc }}$ results of each test agreed well between methods. Equally to $G_{\text {Ic }}$, comparison with reference values cannot be carried out. The percentile differences to the CBBM, once again considered the most robust method, are $3.3 \%$ for the CCM and 22.9 \% for the CBT. The discrepancy for the CBT is linked to the energy dissipated in

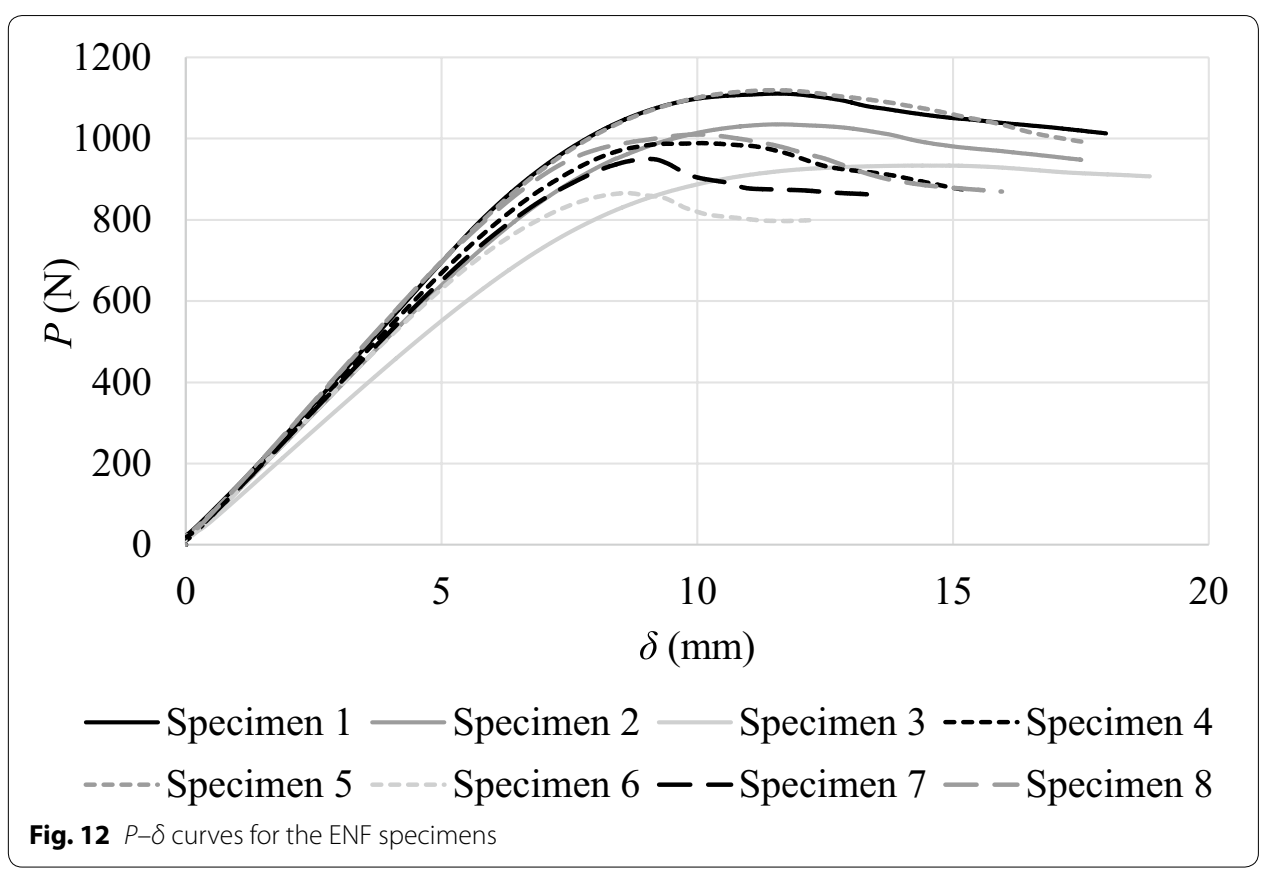




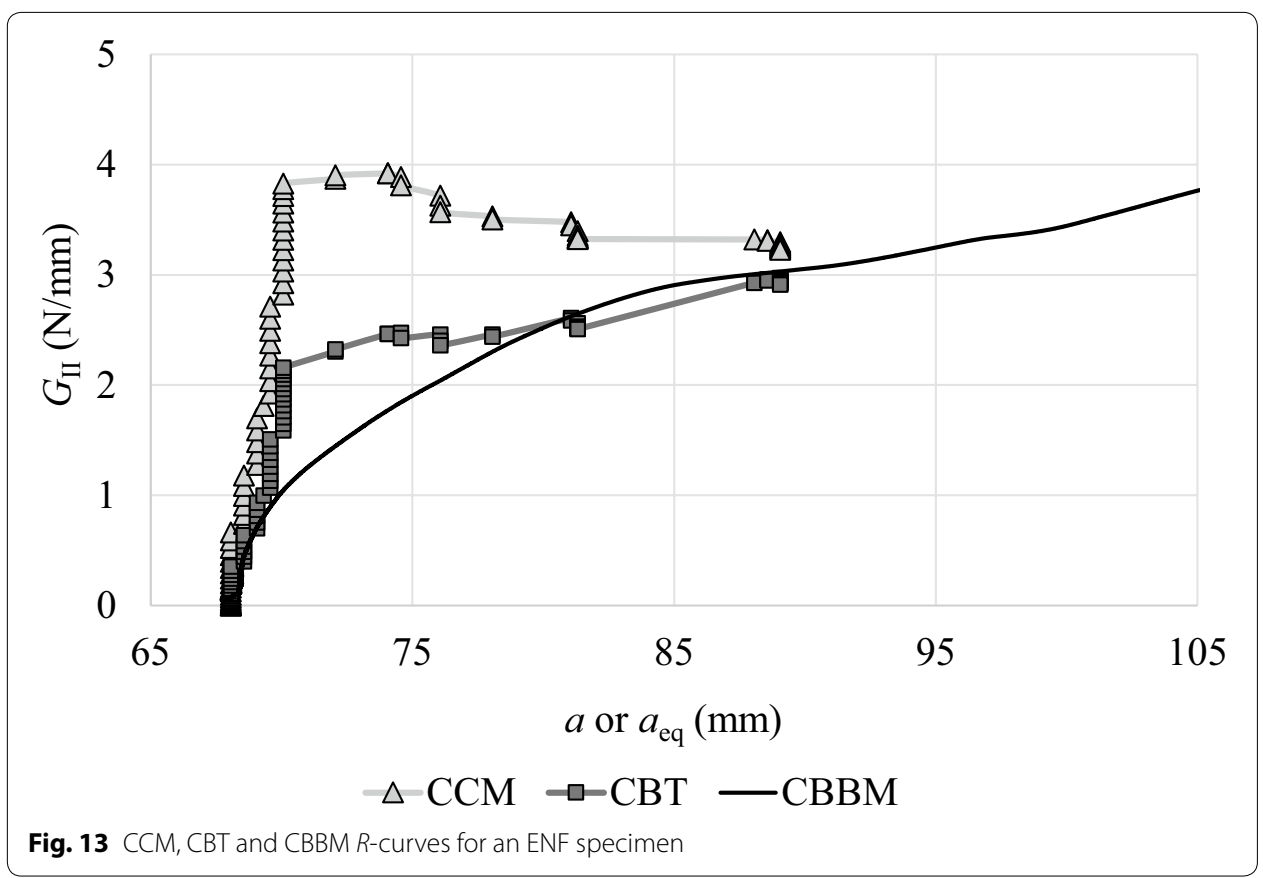

Table 6 Values of $G_{\mathrm{IIc}}$ obtained by the different data reduction methods from the ENF tests

\begin{tabular}{|c|c|c|c|c|c|}
\hline \multirow[t]{2}{*}{ Specimen } & \multirow[t]{2}{*}{$P_{\max }(\mathrm{N})$} & \multirow[t]{2}{*}{$\delta_{\max }(\mathrm{mm})$} & \multicolumn{3}{|c|}{$G_{\mathrm{IIc}}(\mathrm{N} / \mathrm{mm})$} \\
\hline & & & CCM & CBT & CBBM \\
\hline 1 & 1110.912 & 17.990 & 5.183 & 3.327 & 4.467 \\
\hline 2 & 1035.342 & 17.507 & 4.473 & 3.886 & 4.544 \\
\hline 3 & 933.773 & 18.847 & 3.729 & 3.858 & 4.327 \\
\hline 4 & 989.140 & 15.350 & 4.671 & 2.824 & 4.151 \\
\hline 5 & 1119.458 & 17.650 & 5.428 & 3.195 & 4.283 \\
\hline 6 & 866.329 & 12.257 & - & - & - \\
\hline 7 & 950.081 & 13.593 & 3.317 & 2.773 & 3.503 \\
\hline 8 & 1010.304 & 15.953 & 3.843 & 2.984 & 4.367 \\
\hline Average & 1001.917 & 16.143 & 4.378 & 3.264 & 4.235 \\
\hline Standard deviation & 86.818 & 2.303 & 0.783 & 0.459 & 0.347 \\
\hline
\end{tabular}

the FPZ, which is not accounted for in beam theories. Comparing the different specimens for each method, the percentile deviations were 17.9, 14.1 and $8.2 \%$ for the CCM, CBT and CBBM, by this order. The CBBM results of the adhesive Sikapower ${ }^{\circledR} 4720$ gave $G_{\text {IIc }}=4.235 \pm 0.347 \mathrm{~N} / \mathrm{mm}$, which is a slightly smaller value than that obtained for the Araldite ${ }^{\circledR} 2015$, of $G_{\text {IIc }}=4.70 \pm 0.34 \mathrm{~N} / \mathrm{mm}[30]$.

\section{Conclusions}

The main objective of this work was the complete mechanical and fracture characterization of a new epoxy adhesive (Sikapower ${ }^{\circledR} 4720$ ). Bulk tensile and TAST tests were performed to obtain the tensile and shear mechanical properties, respectively. The bulk tensile tests gave the following values: $E=2052.477 \pm 84.818 \mathrm{MPa}$, 
$\sigma_{\mathrm{y}}=23.286 \pm 2.252 \mathrm{MPa}, \sigma_{\mathrm{f}}=27.519 \pm 0.845 \mathrm{MPa}$, and $\varepsilon_{\mathrm{f}}=1.973 \pm 0.343 \%$. From the manufacturer's data, only $\sigma_{\mathrm{f}}(24 \mathrm{MPa}), E(1900 \mathrm{MPa})$ and $\varepsilon_{\mathrm{f}}(3 \%)$ were available. The biggest difference was found in $\varepsilon_{\mathrm{f}}$, justified by small experimental defects in the specimens that could compromise the full ductility of the specimens to develop. The TAST tests resulted in $G=750.738 \pm 46.356 \mathrm{MPa}, \tau_{\mathrm{y}}=14.876 \pm 1.012 \mathrm{MPa}, \tau_{\mathrm{f}}=24.341 \pm 0.941$ and $\gamma_{\mathrm{f}}=23.150 \pm 7.859 \%$. The only comparison with the manufacturer's data regards $\tau_{\mathrm{f}}(14 \mathrm{MPa})$, which corresponds to a significant difference to the obtained value in this work. However, the manufacturer's value was empirically defined by the von Mises criterion which, as it is known, does not apply to toughened adhesives. The availability of $E$ and $G$ permits the calculation of $v$ for isotropic materials as 0.367 , which is within the interval of expected values for structural adhesives, i.e., between 0.3 and 0.5 [1]. The $G_{\text {Ic }}$ values, obtained by DCB tests, gave $1.201 \pm 0.138 \mathrm{~N} / \mathrm{mm}(\mathrm{CCM}), 1.278 \pm 0.132 \mathrm{~N} /$ $\mathrm{mm}(\mathrm{CBT})$ and $1.294 \pm 0.182 \mathrm{~N} / \mathrm{mm}(\mathrm{CBBM})$, corresponding to a good correspondence between methods. The ENF tests provided the $G_{\text {IIc }}$ estimations as $4.378 \pm 0.783 \mathrm{~N} / \mathrm{mm}$ $(\mathrm{CCM}), 3.264 \pm 0.459 \mathrm{~N} / \mathrm{mm}$ (CBT) and $4.235 \pm 0.347 \mathrm{~N} / \mathrm{mm}$ (CBBM). As previously mentioned, the CBT under predicted the other methods. It was not possible to compare $G_{\text {Ic }}$ and $G_{\text {IIc }}$ with the manufacturer's values due to the absence of information. The comparison of the obtained results with the Araldite ${ }^{\circledR} 2015$ revealed better properties in all parameters except $\varepsilon_{\mathrm{f}}, \gamma \mathrm{f}$ and $G_{\mathrm{IIC}}$, in this last parameter by a very short difference.

\section{Authors' contributions}

JPRM - carried out the experimental tests and analyses. RDSG, EASM and LFMS wrote the manuscript. All authors read and approved the final manuscript.

\section{Author details}

${ }^{1}$ Departamento de Engenharia Mecânica, Instituto Superior de Engenharia do Porto, Instituto Politécnico do Porto, Rua Dr. António Bernardino de Almeida, 431, 4200-072 Porto, Portugal. ${ }^{2}$ Instituto de Ciência e Inovação em Engenharia Mecânica e Engenharia Industrial (INEGI), Rua Dr. Roberto Frias, 4200-465 Porto, Portugal. ${ }^{3}$ Departamento de Engenharia Mecânica, Faculdade de Engenharia, Universidade do Porto, Rua Dr. Roberto Frias, 4200-465 Porto, Portugal.

\section{Acknowledgements}

The authors would like to thank Sika ${ }^{\circledR}$ Portugal for supplying the adhesive Sikapower ${ }^{\circledR} 4720$.

\section{Competing interests}

The authors declare that they have no competing interests.

Received: 17 November 2015 Accepted: 14 December 2015

Published online: 22 December 2015

\section{References}

1. Silva LFM, Öchsner A, Adams RD. Handbook of adhesion technology. 1st ed. Berlin: Springer; 2011.

2. Needleman A. A continuum model for void nucleation by inclusion debonding. J Appl Mech. 1987;54:525-31.

3. Tvergaard $\mathrm{V}$, Hutchinson JW. The relation between crack growth resistance and fracture process parameters in elastic-plastic solids. J Mech Phys Solids. 1992;40:1377-97.

4. Camacho GT, Ortiz M. Computational modelling of impact damage in brittle materials. Int J Solids Struct. 1996:33:2899-938.

5. Banea MD, da Silva LFM, Campilho RDSG. Effect of temperature on the shear strength of aluminium single lap bonded joints for high temperature applications. J Adhes Sci Technol. 2014;28:1367-81.

6. ISO 527-5 Standard. 1997. Plastics-determination of tensile properties. Geneva, Switzerland.

7. ASTM D638-03 Standard. 2014. Standard test method for tensile properties of plastics. West Conshohocken, USA

8. ISO 11003-2 Standard. 1993. Adhesives-determination of shear behaviour of structural bonds - part 2: thickadherend tensile-test method. Geneva, Switzerland.

9. ASTM E143-02 Standard. 2013. Standard test method for shear modulus at room temperature. West Conshohocken, USA.

10. ISO 25217 Standard. 2009. Adhesives-determination of the mode 1 adhesive fracture energy of structural adhesive joints using double cantilever beam and tapered double cantilever beam specimens. Geneva, Switzerland.

11. Kanninen MF, Popelar CH. Advanced fracture mechanics. Oxford: Oxford University Press; 1985.

12. Ding W. 1999. Delamination analysis of composite laminates. PhD Thesis. University of Toronto, Canada. 
13. Robinson P, Das S. Mode I DCB testing of composite laminates reinforced with z-direction pins: a simple model for the investigation of data reduction strategies. Eng Fract Mech. 2004;71:345-64.

14. de Moura MFSF, Campilho RDSG, Gonçalves JPM. Crack equivalent concept applied to the fracture characterization of bonded joints under pure mode I loading. Compos Sci Technol. 2008;68:2224-30.

15. de Moura MFSF, Gonçalves JPM, Chousal JAG, Campilho RDSG. Cohesive and continuum mixed-mode damage models applied to the simulation of the mechanical behaviour of bonded joints. Int J Adhes Adhes. 2008;28:419-26.

16. Saldanha DFS, Canto C, da Silva LFM, Carbas RJC, Chaves FJP, Nomura K, Ueda T. Mechanical characterization of a high elongation and high toughness epoxy adhesive. Int J Adhes Adhes. 2013;47:91-8.

17. García JA, Chiminelli A, García B, Lizaranzu M, Jiménez MA. Characterization and material model definition of toughened adhesives for finite element analysis. Int J Adhes Adhes. 2011;31:182-92.

18. Jin H, Miller GM, Pety SJ, Griffin AS, Stradley DS, Roach D, Sottos NR, White SR. Fracture behavior of a self-healing, toughened epoxy adhesive. Int J Adhes Adhes. 2013;44:157-65.

19. Kim BC, Park SW, Lee DG. Fracture toughness of the nano-particle reinforced epoxy composite. Compos Struct. 2008;86:69-77.

20. NFT 76-142 Standard. 1988. Méthode de préparation de plaques d'adhésifs structuraux pour la réalisation d'éprouvettes d'éssai de caractérisation. La Plaine Saint-Denis. France.

21. Pinto SDM. 2013. Determinação das propriedades mecânicas à tração de adesivos estruturais frágeis e dúcteis. MSC Thesis. Instituto superior de Engenharia do Porto, Porto.

22. Morais JFA. 2013. Desenvolvimento de ferramentas e provetes para o ensaio thick adherend shear test (TAST). MSC Thesis. Instituto superior de Engenharia do Porto, Porto.

23. Campilho RDSG, Banea MD, Pinto AMG, da Silva LFM, de Jesus AMP. Strength prediction of single- and double-lap joints by standard and extended finite element modelling. Int J Adhes Adhes. 2011;31:363-72.

24. Banea MD, da Silva LFM, Campilho RDSG. Effect of temperature on tensile strength and mode I fracture toughness of a high temperature epoxy adhesive. J Adhes Sci Technol. 2012;26:939-53.

25. ISO 15024 Standard. 2011. Fibre-reinforced plastic composites-determination of mode I interlaminar fracture toughness, GIC, for unidirectionally reinforced materials. Geneva, Switzerland.

26. Campilho RDSG, Moura DC, Gonçalves DJS, da Silva JFMG, Banea MD, da Silva LFM. Fracture toughness determination of adhesive and co-cured joints in natural fibre composites. Compos Part B Eng. 2013;50:120-6.

27. de Moura MFSF, Campilho RDSG, Gonçalves JPM. Pure mode II fracture characterization of composite bonded joints. Int J Solids Struct. 2009;46:1589-95.

28. Compston P, Jar PYB, Burchill PJ, Takahashi K. The effect of matrix toughness and loading rate on the mode-II interlaminar fracture toughness of glass-fibre/vinyl-ester composites. Compos Sci Technol. 2001;61:321-33.

29. Wang Y, Williams JG. Corrections for mode II fracture toughness specimens of composite materials. Compos Sci Technol. 1992;43:251-6.

30. Campilho RDSG, Banea MD, Neto JABP, da Silva LFM. Modelling adhesive joints with cohesive zone models: effect of the cohesive law shape of the adhesive layer. Int J Adhes Adhes. 2013;44:48-56.

31. Shahverdi M, Vassilopoulos AP, Keller T. Modeling effects of asymmetry and fiber bridging on Mode I fracture behaviour of bonded pultruded composite joints. Eng Fract Mech. 2013;99:335-48.

\section{Submit your manuscript to a SpringerOpen ${ }^{\circ}$ journal and benefit from:}

- Convenient online submission

- Rigorous peer review

- Immediate publication on acceptance

- Open access: articles freely available online

- High visibility within the field

- Retaining the copyright to your article

Submit your next manuscript at $\mathbf{s p r i n g e r o p e n . c o m ~}$ 